\title{
Inhibition of Marfan Syndrome Aortic Root Dilation by Losartan
}

\section{Role of Angiotensin II Receptor Type 1-Independent Activation of Endothelial Function}

Stephanie L. Sellers, ${ }^{* \pi}$ Nadia Milad, ${ }^{* \pi}$ Rayleigh Chan, ${ }^{* \pi}$ Michael Mielnik, ${ }^{* \pi}$ Una Jermilova, ${ }^{* \pi}$ Paul L. Huang, ${ }^{\ddagger}$ Rini de Crom, ${ }^{\S}$

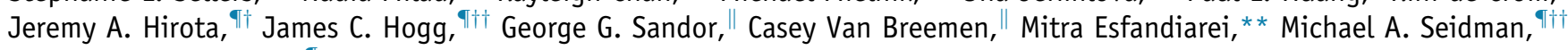
and Pascal Bernatchez ${ }^{* \mathbb{T}}$

From the Department of Anesthesiology, Pharmacology and Therapeutics, * the UBC Centre for Heart Lung Innovation and St. Paul's Hospital, ${ }^{\circledR}$ the Division of Respiratory Medicine, Department of Medicine, Chan-Yeung Centre for Occupational and Environmental Respiratory Disease, ${ }^{\dagger}$ the Department of Pathology and Laboratory Medicine, ${ }^{\dagger \dagger}$ Providence Health Care, and the Child and Family Research Institute, $\|$ University of British Columbia (UBC), Vancouver, British Columbia, Canada; the Cardiovascular Research Centre, ${ }^{\ddagger}$ Massachusetts General Hospital, Harvard University, Charlestown, Massachusetts; the Department of Cell Biology and Genetics, ${ }^{\S}$ Erasmus University Medical Center, Rotterdam, the Netherlands; and the Department of Biomedical Sciences, ** Midwestern University, Glendale, Arizona

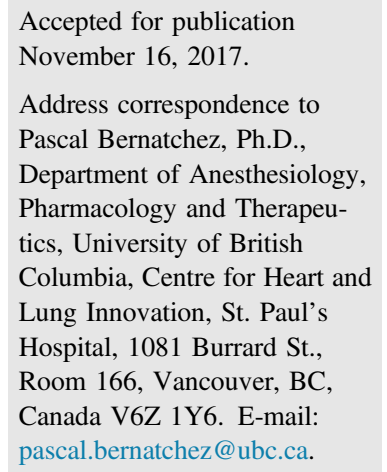

\begin{abstract}
Marfan syndrome (MFS) is a genetic disorder that frequently leads to aortic root dissection and aneurysm. Despite promising preclinical and pilot clinical data, a recent large-scale study using antihypertensive angiotensin II (AngII) receptor type 1 (ATR1) blocker losartan has failed to meet expectations at preventing MFS-associated aortic root dilation, casting doubts about optimal therapy. To study the deleterious role of normal ATR1 signaling in aortic root widening, we generated MFS mice lacking ATR1a expression in an attempt to preserve protective ATR2 signaling. Despite being hypotensive and resistant to AngII vasopressor effects, MFS/ATR1a-null mice showed unabated aortic root enlargement and remained fully responsive to losartan, confirming that blood pressure lowering is of minor therapeutic value in MFS and that losartan's antiremodeling properties may be ATR1 independent. Having shown that MFS causes endothelial dysfunction and that losartan can activate endothelial function in mice and patients, we found that nitric oxide synthase (NOS) inhibition renders losartan therapeutically inactive, whereas multiple transgenic and pharmacologic models of endothelial NOS activation block aortic root dilation by correcting extracellular signal-regulated kinase signaling. In vitro, losartan can increase endothelial NO release in the absence of AngII and correct MFS NO levels in vivo. Our data suggest that increased protective endothelial function, rather than ATR1 inhibition or blood pressure lowering, might be of therapeutic significance in preventing aortic root disease in MFS. (Am J Pathol 2018, 188: 574-585; https://doi.org/10.1016/j.ajpath.2017.11.006)
\end{abstract}

Supported by a Canadian Institutes of Health Research (CIHR) grant (C.V.B., M.E., and P.B.), the Heart and Stroke Foundation of British Columbia \& Yukon (P.B.), the Yukon and Canadian Foundation for Innovation (P.B.), the Michael Smith Foundation for Health Research (P.B.), CIHR New Investigator Awards (P.B. and J.A.H.), CIHR studentship funding (S.L.S.), the CIHR Michael Smith Foreign Study Fund
(S.L.S.), University of British Columbia studentship funding (S.L.S.), a Frank \& Marilyn Anfield Distinguished Heart Center Scholar Award (M.A.S.), the Early Career Research Initiative (M.A.S.), and a Designated Ward-Research Award from the St. Paul's Foundation (M.A.S.).

Disclosures: None declared. 
Marfan syndrome (MFS) is an autosomal dominant connective tissue disorder caused by mutations in the fibrillin-1 $(F B N I)$ gene, with an estimated prevalence of 1:5000. ${ }^{1}$ FBN1 plays a key role in formation and stabilization of elastic fibers that provide aortic recoil during systole ${ }^{1}$ and in regulating quiescence of transforming growth factor- $\beta$ (TGF- $\beta$ ), a pluripotent cytokine believed to be a causative factor in the pathogenesis of MFS. ${ }^{2}$ Of the diverse manifestations of MFS, progressive aortic root dilation is the most serious because it is associated with increasing risk of acute aortic dissection ${ }^{3,4}$ and death. ${ }^{5-8}$ Hence, pharmacotherapy aimed at slowing the rate of dilation is key to patient management. The antihypertensive medication losartan, an angiotensin II (AngII) receptor type 1 (ATR1) blocker, ${ }^{9}$ is recommended by current treatment guidelines because of unique antiremodeling properties ${ }^{7}$ that are not observed with either angiotensin-converting enzyme inhibitors or $\beta$ blockers. ${ }^{9,10}$ Losartan was shown to decrease the rate of aortic root dilation in rodent models of MFS and in pediatric patients refractory to $\beta$-blocker treatment. ${ }^{7,11}$ Yet, a large multicenter trial failed to show the expected superiority of losartan treatment over atenolol, ${ }^{12}$ which further stirred debate about optimal MFS patient management.

Mechanistic and pharmacologic studies have suggested that losartan decreases aortic root dilation by blocking deleterious AngII-ATR1 signaling while preserving protective AngII-ATR2 interactions, something not achieved by angiotensin-converting enzyme inhibitors because of their inhibitory effect on AngII synthesis. ${ }^{7}$ Both ATR1 blockers and angiotensin-converting enzyme inhibitors can attenuate canonical ATR1-driven TGF- $\beta$ signaling, which is Smad dependent. However, AngII-ATR2 signaling preserved by losartan results in lower noncanonical TGF- $\beta$ activation of the extracellular signal-regulated kinase pathway and protection against aberrant growth and rupture of the aorta. ${ }^{13}$ Whether this unique property of losartan can rationalize its unexpected therapeutic properties in non-AngII-driven lung disease ${ }^{14}$ remains to be determined.

To better understand losartan's complex antiremodeling properties, MFS mice were generated with blunted cardiac and aortic root AngII/ATR1 signaling on the basis of the premise that the resultant animals would not only be protected against MFS-associated cardiomyopathy. ${ }^{15}$ They would also be protected against aortic root dilation through lower pathological ATR1 signaling and preserved ATR2dependent protection of the aortic wall. To our surprise, despite conferring protection against MFS cardiomyopathy, ${ }^{15}$ loss of ATR1a did not confer any protection against the aortic manifestations of MFS, despite causing hypotension, blunted AngII pressor responses, and decreased heart rate (HR). Moreover, these animals were neither resistant nor hypersensitive to losartan, suggesting that its mechanism of action is more complex than a simple ATR2-protective ${ }^{13}$ switch in AngII signaling and may include ATR1-independent effects. Instead, inhibition of nitric oxide synthase (NOS) activity renders losartan inactive, whereas multiple transgenic and pharmacologic approaches that activate the endothelial NOS-derived NO pathway can attenuate MFS aortic root remodeling in vivo. Hence, we suggest that losartan can decrease the rate of aortic root remodeling via endothelial function activation, possibly in an off-target manner, and that reversing MFSassociated endothelial dysfunction may be of therapeutic value in MFS.

\section{Materials and Methods}

\section{Animals}

Marfan mice (fibrillin $\mathrm{C}_{1039 \mathrm{G}^{+/-}}$) were originally supplied from the laboratory of Dr. Harry Dietz (Johns Hopkins School of Medicine, Baltimore, MS) and maintained in the Genetically Engineered Models facility at the Center for Heart Lung Innovation. ATR1a-knockout mice $\left(\mathrm{ATR}_{1}{ }^{-/-}\right.$; stock number 002682) were purchased from The Jackson Laboratory (Bar Harbor, ME) and maintained in the Genetically Engineered Models facility at the Center for Heart Lung Innovation. Marfan mice lacking ATR1 expression were generated by crossing of MFS and ATR $1 \mathrm{a}^{-/-}$mice to give MFS ATR $1^{+/-}$mice, which were subsequently crossed together to generate MFS ATR $1 \mathrm{a}^{-1-}$ mice and littermate controls. MFS phosphorylated mimetic S1176D knock-in mice and phosphorylated inactive S1176A knock-in mice were generated in a similar manner, with knock-in strains originally supplied by Dr. Paul Huang (Harvard Medical School, Boston, MA). ${ }^{16}$ MFS containing endothelial NOS (eNOS) transgenes and controls were generated using littermates from crosses of MFS with eNOS hemizygous transgenic animals supplied by R.d.C. ${ }^{17}$ Animals were randomly assigned to groups on weaning by a technician blind to genotype; group sizes were based on estimates derived from previously noted phenotypes of the C1039G model. ${ }^{7}$ Animals were excluded on weaning in the rare event of abnormality (eg, malocculation) as predetermined under the University of British Columbia Animal Care Guidelines. All animals were housed in the Genetically Engineered Models facility at the Center for Heart Lung Innovation on a standard 12-hour light/dark cycle, fed standard laboratory chow, and maintained using breeding and procedures approved by the University of British Columbia Animal Care Committee.

\section{Losartan, L-NAME, and CavN0xin Treatment}

Losartan treatment was provided via drinking water $(0.6 \mathrm{~g} / \mathrm{L})$ starting at 6 weeks of age (MFS, $n=11$; MFS/ATR $1 \mathrm{a}^{-/-}$, $n=5$ ). L-NG-Nitroarginine methyl ester (L-NAME; Sigma, St. Louis, MO; $0.5 \mathrm{mg} / \mathrm{mL}$ ) was given alone (control) or in combination with losartan in drinking water starting at 6 weeks of age and was also administered via i.p. injection (10 $\mathrm{mg} / \mathrm{kg}$ ) biweekly for the first 2 weeks (MFS, $n=5$ per group). 

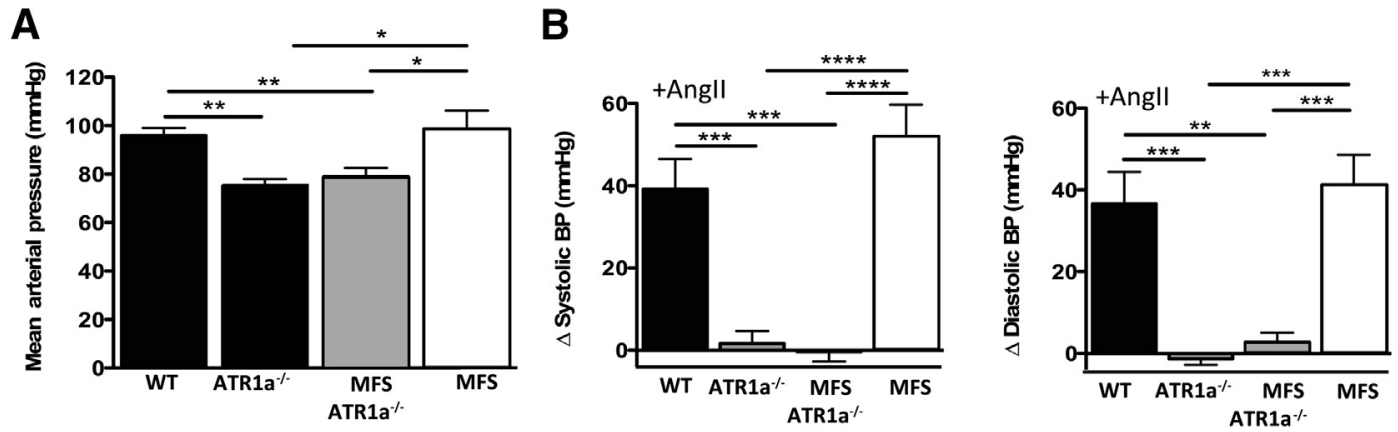

C
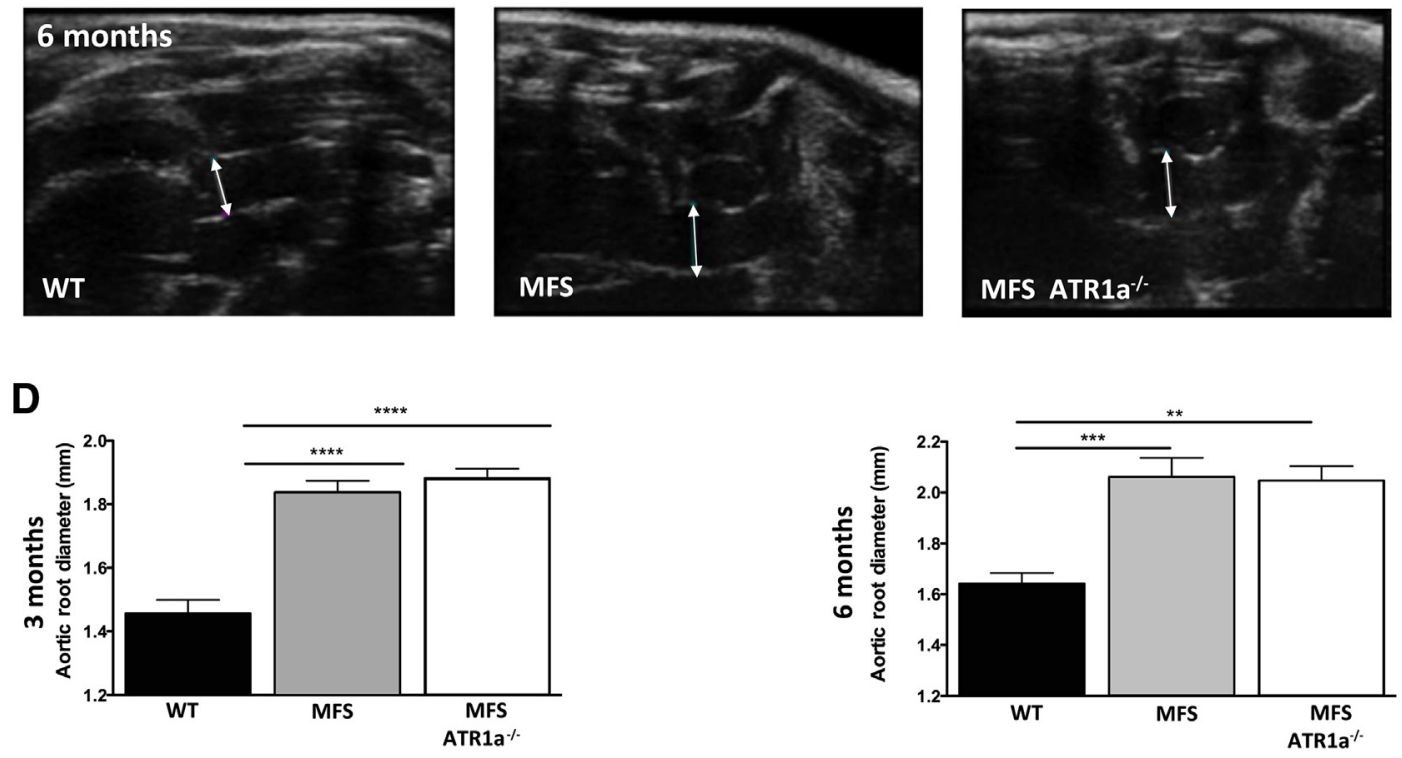

E
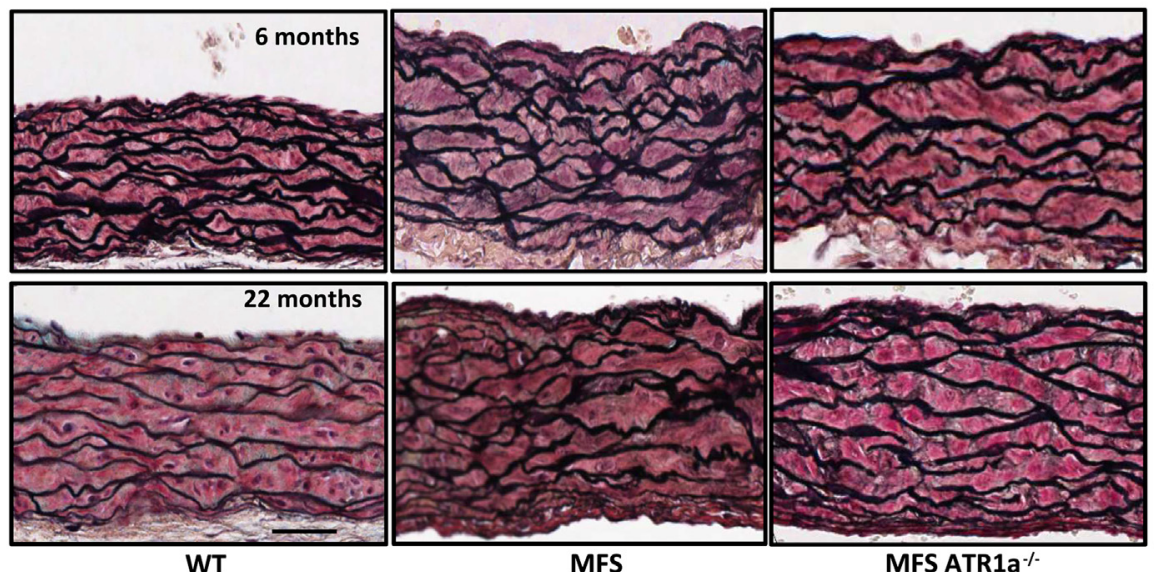

$\mathbf{F}$
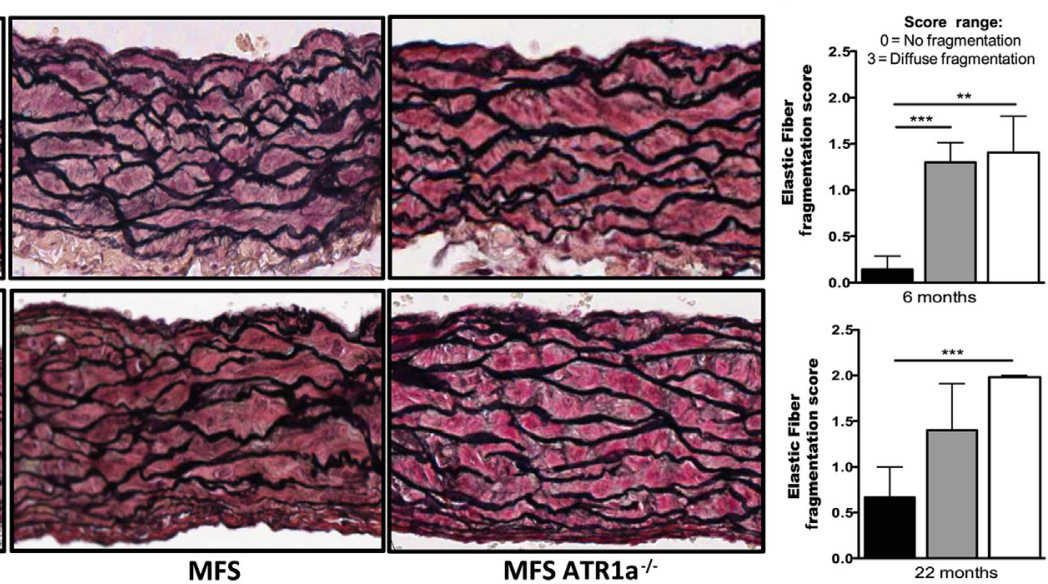

G

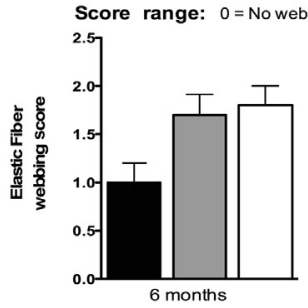

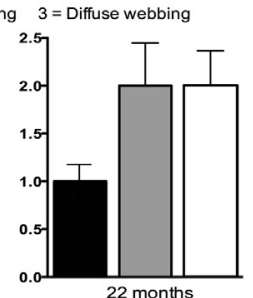

H

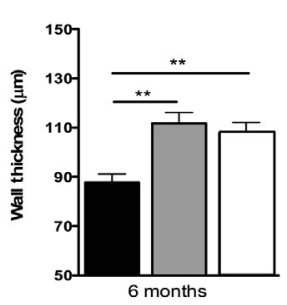


CavNOxin [MFS, $n=7$; wild type (WT), $n=6$ ] was given via i.p. injections, as previously described. ${ }^{18,19}$

\section{ATR1a Expression and AngII Blood Pressure Response}

Disruption of the ATRla gene was confirmed in ATR1a ${ }^{-1-}$ mice via PCR (primer sequences: $5^{\prime}$-TGAGAACACCAATATCACTG-3', 5'-TTCGTAGACAGGCTTGAG- $3^{\prime}$, and $5^{\prime}$-CCTTCTATCGCCTTCTTGACG-3'; obtained from the Jackson Laboratory). Loss of functional ATR1a response to AngII was confirmed by blood pressure response to acute infusion of AngII. Unsedated baseline systolic and diastolic blood pressure was averaged over a 5-day period using the Kent Scientific Corp. CODA2 (Torrington, CT) in ATR1 $\mathrm{a}^{+/+}$

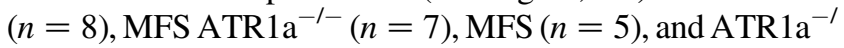
$(n=5)$ mice. Mice were injected i.p. with AngII $(0.2 \mathrm{mg} / \mathrm{kg}$; Sigma), and changes in blood pressure were measured over a 10-minute period to determine peak response to AngII. Changes in blood pressure are expressed as change in systolic and diastolic pressure from baseline at peak response to AngII. Peak blood pressure values were averaged for each mouse over three consecutive measurement cycles.

\section{Histology}

Histology was performed on hearts and lungs fixed in $10 \%$ buffered formalin. Hearts were bisected parallel to the atrioventricular plane and embedded in paraffin. Sections were analyzed every $50 \mu \mathrm{m}$ throughout the aortic root. Elastic fibers were assessed at the sinus of Valsalva on slides stained with Movat's pentachrome by a blinded cardiac pathologist. Elastic fiber fragmentation was scored on a scale of 0 to 3 , wherein 0 indicates no fragmentation; 1 , mild fragmentation $(0 \%$ to $20 \%$ ); 2 , moderate fragmentation ( $20 \%$ to $40 \%$ ); and 3, extensive fragmentation $(>40 \%)$. Observable webbing, defined as interlinking of elastic fibers between concentric layers, was also scored on a scale of 0 to 3 using the same parameters as fragmentation. Histology of the left lung was performed, as previously described, via inflation and paraffin embedding, and air space enlargement was analyzed by mean linear intercept. ${ }^{20}$ Processing, staining, and quantification of histology were performed by technicians blinded to genotype and treatment group. Staining of biotin-conjugated AngII used AngII with avidin-biotin horseradish peroxidase detection and was performed on frozen sections ( $30 \mu \mathrm{m}$ thick) of aortic root and descending aorta in the presence and absence of losartan. Extracellular signal-regulated kinase phosphorylation assays were performed using rabbit polyclonal phosphorylated extracellular signal-regulated kinase 1/2 (202/204) antibodies (Cell Signaling, Danvers, MA) on paraffin-embedded sections exposed to citrate antigen retrieval solutions.

\section{Echocardiograms}

Echocardiograms were performed on mice anesthetized with isoflurane using a VisualSonics (Toronto, ON, Canada) Vevo 2100 system with an MS-550D 40-MHz probe by a technician blinded to genotype and treatment group. Aortic root measurements were averaged from multiple measurements taken in both $\mathrm{M}$ and $\mathrm{B}$ mode at the level of the sinus of Valsalva. ${ }^{21}$ Data for the MFS ATR $1^{-1-}$ strain and controls were analyzed at 3 (WT, $n=11$; MFS, $n=9$; MFS/ATR1a ${ }^{-1-}, n=6$ ) 6 (WT, $n=6$; MFS, $n=7$; MFS/ $\mathrm{ATR} \mathrm{a}^{-/-}, n=6$ ), and 9 (WT, $n=6$; MFS, $n=8$; MFS/

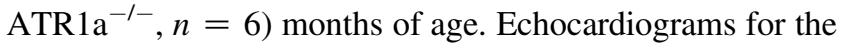
MFS S1176D and MFS eNOS transgene-positive strains and controls were analyzed at 3 months of age (WT, $n=11$; MFS, $n=15$; MFS S1176D, $n=13$; S1176D, $n=9$; and WT, $n=7$; MFS, $n=10$; MFS eNOS transgene positive, $n=7$; eNOS transgene positive, $n=7$, respectively) and at 6 months in the S1176A strain (WT, $n=9$; MFS, $n=10$; MFS S1176A, $n=5$ ).

\section{Cell Culture, TGF- $\beta$, Nitric 0xide Levels, and Western Blot Analysis}

Nitric oxide levels from cell supernatants were quantified by measuring soluble nitrite levels, a stable breakdown product of NO, in the supernatant of cultured bovine aortic endothelial cells (ECs) using a GE/Sievers (Boulder, CO) Nitric Oxide analyzer. Bovine aortic ECs were isolated from freshly harvested aortas, cultured in Dulbecco's modified Eagle's medium (Life Technologies, Burlington, ON, Canada) containing 5\% fetal bovine serum (Hyclone Laboratories, Logan, UT) and antibiotics. Bovine aortic ECs were characterized by their cobblestone monolayer morphology, factor VIII immunohistochemistry, and by diiodo-indocarbocyanide acetylated low-density lipoprotein uptake, as described previously. ECs were grown to confluence, starved, and treated as previously described ${ }^{22}$; absence of Mycoplasma was

Figure 1 Blood pressure reduction and loss of ATR1a expression does not prevent aortic root dilation or progression in Marfan syndrome (MFS). A: Mean arterial pressure was evaluated in wild-type (WT) and MFS mice with ATR1a and without ATR1a (ATR1a ${ }^{-/-}$) expression, as determined by repeated measurements. B: Lack of systolic or diastolic blood pressure (BP) responses to angiotensin II (AngII) injection is seen in ATR1a ${ }^{-/-}$deficient groups, with data presented as differential between pre- and post-AngII values. C and D: Echocardiograms and average aortic root diameters (double-headed arrows) of WT, MFS, and MFS ATR1a ${ }^{-1-}$ mice at 3 and 6 months, as performed by a blinded technician. Data represent average aortic root diameter, wherein diameter was determined by averaging multiple measurements taken in both $\mathrm{M}$ and $\mathrm{B}$ modes. $\mathbf{E}-\mathbf{H}$ : Histology of aortic root sections at the level of the sinus of Valsalva. Sections were stained with Movat's pentachrome at 6 and 22 months of age (E) to determine elastic fiber fragmentation (F), elastic fiber webbing $(\mathbf{G})$, and aortic wall thickness (H). Data are expressed as means \pm SEM (A and $\mathbf{B}) . n=7$ WT $(\mathbf{A}$ and $\mathbf{B})$ and WT at 6 months $(\mathbf{E}-\mathbf{H}) ; n=6$ MFS ATR1a ${ }^{-/-}$and MFS $(\mathbf{A}$ and B), MFS/ATR1a ${ }^{-/-}\left(\mathbf{C}\right.$ and D), and MFS ATR1a ${ }^{-/-}$at 22 months (E-H); $n=11$ WT (C and D); $n=9$ MFS (C and D); $n=10$ MFS at 6 months (E-H); $n=5$ MFS/ATR1a ${ }^{-1-}$ at 6 months and WT and MFS at 22 months $(\mathbf{E}-\mathbf{H}) .{ }^{*} P<0.05,{ }^{* *} P<0.01,{ }^{* * *} P<0.001$, and ${ }^{* * * * P} P<0.0001$ (analysis of variance and $t$-test, with Bonferroni's correction). Scale bar $=100 \mu \mathrm{m}(\mathbf{E})$. 
A
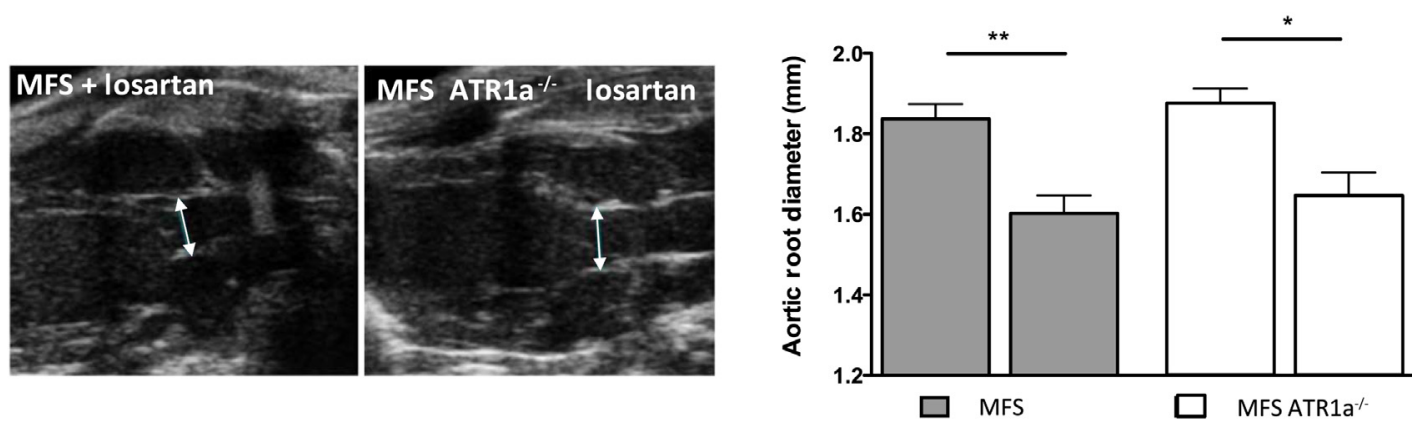

B

Biotin-Angll binding +/- losartan
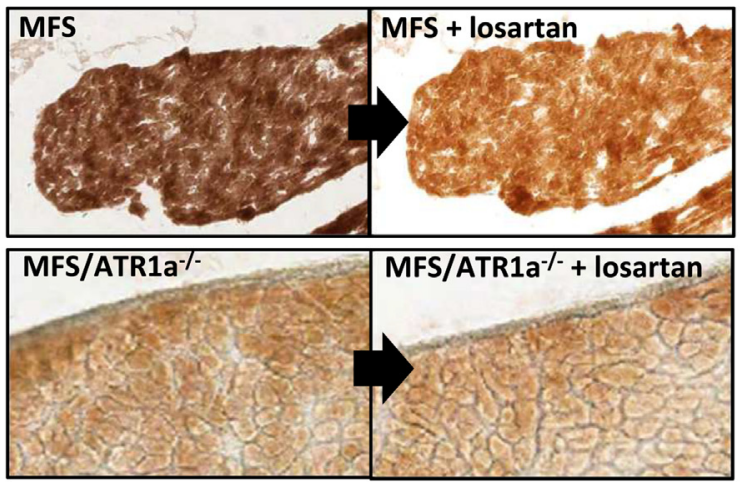

Myocardium (positive ctrl)
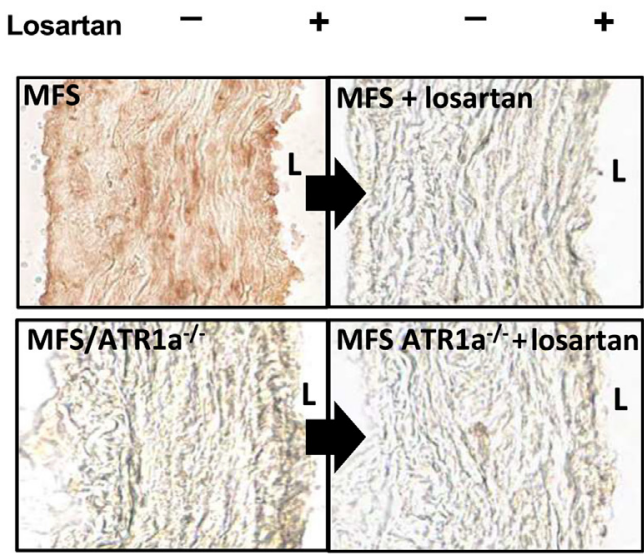

Aortic root

C
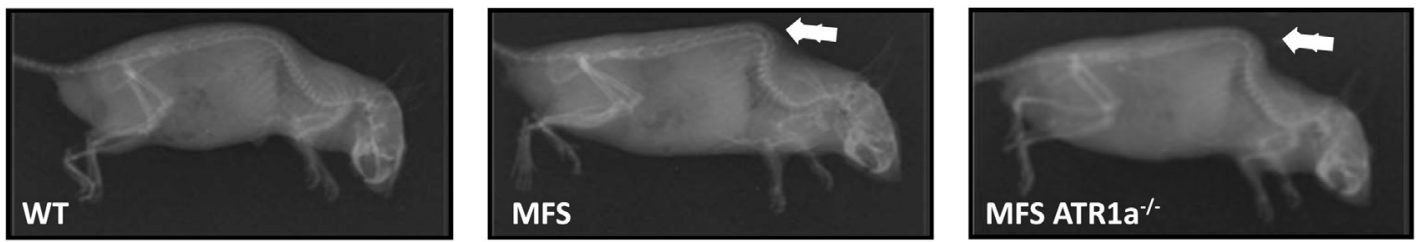

D
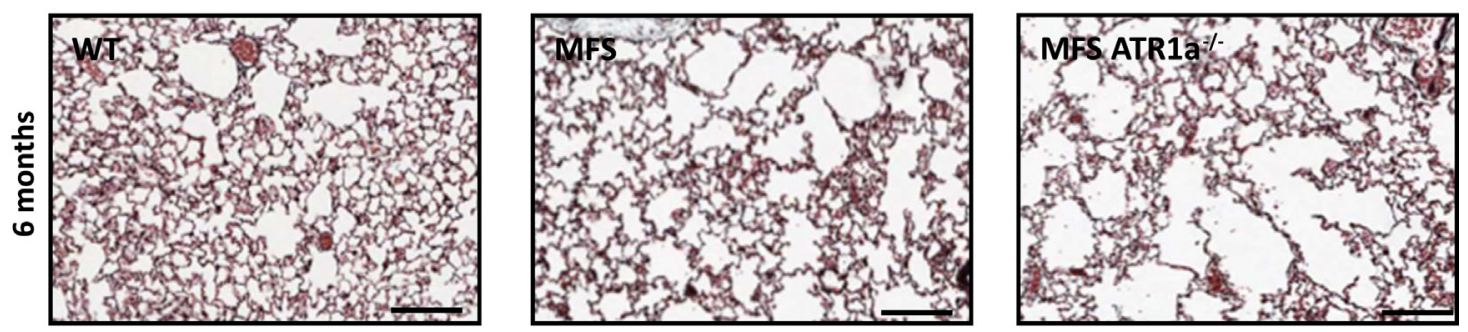

E

F
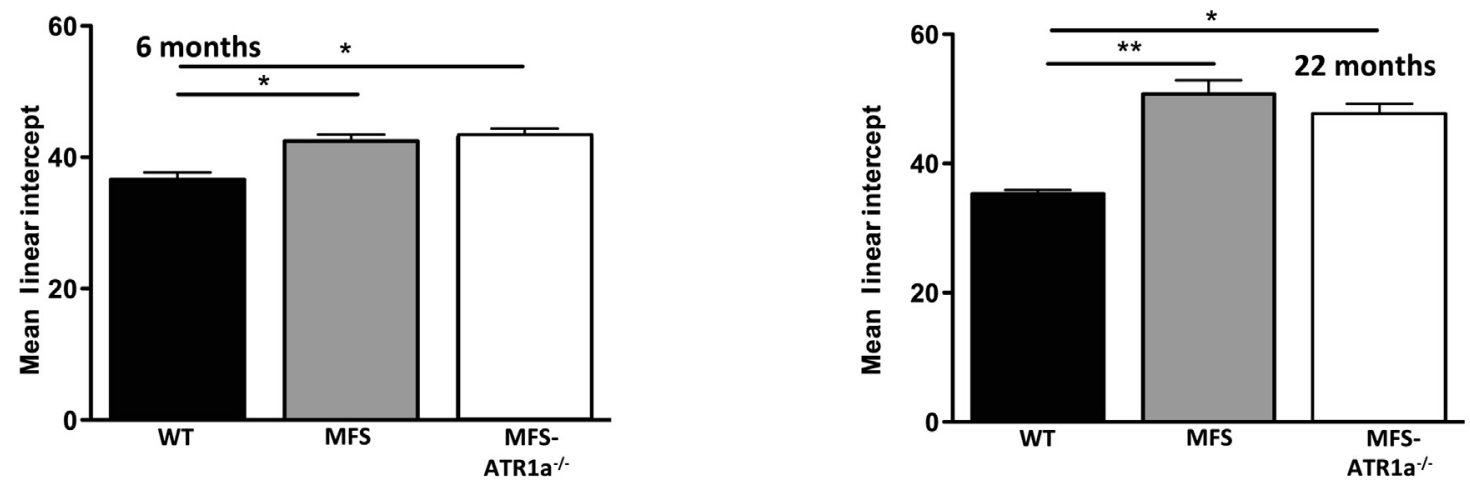
confirmed. Confluent bovine aortic ECs were starved in fetal bovine serum-free Dulbecco's modified Eagle's medium for 24 hours and treated with losartan $\left(10^{-8}, 10^{-7}\right.$, or $10^{-6} \mathrm{~mol} /$ $\mathrm{L}$, as indicated). For studies with vascular endothelial growth factor receptor-2 (VEGFR2) knockdown, ECs were treated with VEGFR2 siRNA (Qiagen, Hilden, Germany; target sequence, CAGAAGTGATTGGAAATGATA). Knockdown was confirmed via Western blot analysis (VEGFR2/Flk-1; 1:1000; Santa Cruz Biotechnology, Dallas, TX) and quantified relative to heat shock protein 90 loading control (1:1000; BD Biosciences, San Jose, CA). Total nitric oxide levels from plasma were assayed using the Enzo Griess reaction kit (Ann Harbor, MI; ADI917-020), as previously described, ${ }^{22}$ using plasma collected from mice fasted for 12 hours at 6 months of age (WT, $n=5$; MFS, $n=9$; MFS $+\operatorname{losartan,} n=5$ ). Total plasma NO levels were correlated to aortic root diameters at 6 months of age in WT and MFS mice.

\section{Statistical Analysis}

Animal experiments were designed to have, with an $\alpha$ level of $0.05,90 \%$ power to detect a $20 \%$ reduction in aortic root dilation as the wanted end point, although the University of British Columbia's reduction of animal use policy encourages early termination of experiments if statistical significance is reached. Groups were compared via a one-way analysis of variance, followed by $t$-test, whereas multiple comparisons were tested with Bonferroni's correction based on normal distributions, with equal variance confirmed by Bartlett's test (significance level of 0.05).

\section{Results}

The contribution of ATR1a to MFS aortic root pathology was evaluated by generating MFS mice $\left(\mathrm{C}_{1039 \mathrm{G}^{+/-}} \mathrm{MFS}\right)$ lacking the AngII/ATR1a axis (ATR1a-null or ATR1a ${ }^{-1-}$ mice), which has been shown to be the lead regulator of endogenous AngII resting mean arterial pressures and heart rate $^{23}$ and the pathogenic AngII receptor in a cardiac-centric model of MFS. ${ }^{15}$ Both WT and MFS mice lacking ATR1a showed lower basal mean arterial pressure (Figure 1A) ${ }^{24}$ and a similar decrease in resting heart rate (28 and 30 minutes ${ }^{-1}$, respectively; data not shown) compared with their ATR1a-expressing controls, as previously demonstrated. ${ }^{23}$ These mice also lacked pressure responses after acute AngII infusion $(0.2 \mathrm{mg} / \mathrm{kg}$ ) (Figure 1B). Although we hypothesized that loss of ATR1a would protect mice against
MFS aortic root dilation as a result of blunted deleterious ATR1a signaling and intact protective ATR2 signaling, ${ }^{13,15}$ we observed comparable aortic root widening in MFS and MFS/ATR $1 \mathrm{a}^{-1-}$ mice $(1.84 \pm 0.04 \mathrm{~mm}$ versus $1.88 \pm 0.03$ $\mathrm{mm}$, respectively) compared with $1.45 \pm 0.04 \mathrm{~mm}$ in WT (Figure 1, C and D) or ATR1a ${ }^{-1-}$ (Supplemental Figures S1 and S2). Similar aneurysm progression was seen in MFS and MFS/ATR $1 \mathrm{a}^{-1-}$ mice at 6 and 9 months (Figure 1D and Supplemental Figure S1). Histological analyses revealed similar increases in elastic fiber fragmentation at 6 months of age in MFS and MFS/ATR1a ${ }^{-1-}$ mice (Figure 1, E-G). These two groups also demonstrated a trend of increased webbing of elastic fibers (Figure 1, E-G) and a significant increase in aortic wall thickness (Figure 1E), a pattern of pathology also seen at later time points (Figure 1H). Collectively, this demonstrates that on both a histological and whole organ level, MFS mice do not benefit from deletion of ATR1a, which challenges our initial hypothesis of protection against the aortic manifestations of MFS in ATR1a-null mice. In contrast to MFS-associated cardiomyopathy, ${ }^{15}$ hypotension, lower HR, and blunted ATR1a signaling, with the expected shift toward protective ATR2 signaling, ${ }^{13}$ do not prevent MFS-associated aortic root pathology.

To rationalize the unexpected observation of persistent aortic disease in MFS mice lacking ATR1a, their response to losartan was studied. A similar reduction in aortic root diameter was observed in both MFS and MFS/ATR $1 a^{-1-}$ mice (Figure 2A), and prevention of elastic fiber fragmentation (Supplemental Figure S3) was observed with losartan in drinking water $(0.6 \mathrm{~g} / \mathrm{L})$. Considering the dose of losartan used is submaximal, ${ }^{25}$ loss of ATR1a does not increase sensitivity to losartan, which would be expected in a shift toward protective ATR2 signaling in animals lacking ATR1a. Conversely, this may also indicate that the effect of losartan on MFS aortic root dilation may be ATR1a independent or that ATR1a ${ }^{-1-}$ tissues show ATR1b compensation, an unlikely possibility based on past reports. ${ }^{26}$ With the knowledge that ATR antibodies are notorious for their established non-specificity, ${ }^{27,28}$ the lack of ATR1b compensation in ATR1a tissues was confirmed by comparing the losartan-sensitive binding of biotin-AngII on frozen aortic root sections from animals with normal or lacking ATRla gene. In MFS myocardium (positive control for high ATR1ab and ATR2 expression), robust biotinAngII binding was detected (Figure 2B), whereas pretreatment of sections with losartan (which does not block ATR2)

\footnotetext{
Figure 2 Loss of ATR1a expression does not prevent systemic manifestations of Marfan syndrome (MFS) or losartan activity. A: MFS and MFS/ATR1a ${ }^{-/-}$ groups were treated with losartan. Echocardiogram and averaged quantification of aortic root diameter (double-headed arrows) show similar reduction in both MFS and MFS/ATR1a ${ }^{-1-}$ mice treated with losartan at 3 months of age. B: After convincing control experiments using myocardium tissues, biotinconjugated angiotensin II (AngII) is bound to wild-type (WT) or ATR1a-null aortic root with (+losartan) and without losartan. The differential signal is interpreted as the total level of ATR1 (in WT tissues) or ATR1b (in ATR1a ${ }^{-/-}$tissues) present. C: Lateral radiographs to assess kyphosis (white arrows) in ${\mathrm{C} 1039^{+/-} \text {and MFS/ATR1a }}^{-/-}$groups relative to control (WT) in representative images. D-F: Histology of inflated lungs relative to control (Mason's trichrome stain) at 6 and 22 months of age, as quantified by mean linear intercept. $n=9$ MFS (A); $n=11$ MFS + losartan (A) and MFS at 6 months (D-F); $n=5$ MFS ATR1a $^{-/-}$and MFS ATR1a ${ }^{-/-}+$losartan (A) and WT and MFS ATR1a ${ }^{-1-}$ at 6 months and WT and MFS at 22 months (D-F); $n=6$ MFS ATR1a ${ }^{-/-}$at 22 months (D-F). ${ }^{*} P<0.05,{ }^{*} P<0.01$ (analysis of variance and $t$-test). Scale bars $=100 \mu \mathrm{m}$ (D). L, lumen.
} 
decreased biotin-AngII binding (Figure 2B). This indicated high losartan-sensitive ATR1 expression ( $a$ and/or b isoforms) and significant ATR2 expression (resistant to losartan). However, use of MFS/ATR1a ${ }^{-l-}$ myocardium decreased biotin-AngII binding compared with MFS myocardium (Figure 2B) and completely blunted losartan's effect, indicating lack of ATR $1 \mathrm{~b}$ compensation in ATR $1 \mathrm{a}^{-1-}$ myocardium, with normal ATR2 expression (myocardium controls without biotin-AngII show no staining; data not shown). In MFS aortic root tissues, biotin-AngII binding was detected (Figure 2B), albeit to lower levels than in myocardium; however, losartan preincubation almost completely blocked biotin-AngII detection, indicating significant ATR1 expression in MFS aortic root with low levels of AT2R. Most important, use of MFS/ATR1a ${ }^{--}$aortic root sections showed marginal biotin-AngII binding and rendered losartan inactive, indicating lack of both ATR1a expression and ATR $1 b$ compensation in MFS aortic root with an inactivated ATRI gene. This supports the concept of off-target effects by losartan because ATRla gene knockout blunts all ATR1 expression in the aortic root. Moreover, the low aortic root expression of ATR2, indicated by the marginal biotinAngII detection in MFS aortic root preincubated with losartan, suggests that the protective shift toward ATR2 signaling theory in MFS animals treated with losartan might be of less importance than expected. ${ }^{13}$

Nonaortic, non-ATR1-driven MFS pathology was also investigated, and it was found that kyphosis was easily appreciated in both MFS mice and MFS/ATR $1 \mathrm{a}^{-1-}$ mice (Figure 2C), as expected. Moreover, airspace enlargement was notable at 6 months (Figure 2D), with progression seen at 22 months of age (Figure 2, E and F, and Supplemental Figure S3) in both MFS mice and MFS/ATR1a ${ }^{-1-}$ mice compared with wild-type controls, with similar airspace widening by histology (Figure 2, D-F). Finally, evaluation of ATR1a ${ }^{-1-}$ mice showed no cofounding phenotype (Supplemental Figure S2). Therefore, these findings suggest that skeletal and pulmonary pathologies of MFS in the C1039G model are independent of ATR1a, as suggested by others.

Our group and others have reported abnormal endothelial function in murine MFS models and patients, ${ }^{29,30}$ which may lead to abnormal cardiac and vascular remodeling. ${ }^{19,31}$ Most important, we have described how losartan can normalize vascular function, including acetylcholineinduced vasorelaxation $\mathrm{EC}_{50},{ }^{32}$ in early MFS aortic disease. Losartan can increase MFS patient flow-mediated dilation, ${ }^{33}$ a marker of endothelial function and heightened NO bioavailability, two biological properties not shared by atenolol. ${ }^{34}$ Hence, we investigated whether losartan's effect on MFS aortic root disease may be NO dependent. Treatment of MFS mice with NOS inhibitor L-NAME rendered losartan therapeutically inactive (Figure 3, A and B), confirming that losartan has endothelial function-dependent effects, as suggested by others. ${ }^{35}$ In vivo, MFS mice showed decreased plasma $\mathrm{NO}$ levels relative to control, which were corrected with losartan treatment (Figure 3C). Furthermore, increasing aortic root diameter was found to correlate with reduced plasma NO $\left(\mathrm{R}^{2}=0.8\right)$ (Figure $\left.3 \mathrm{D}\right)$. In vitro, cultured aortic ECs were challenged with losartan under acute and chronic conditions in absence of exogenous AngII, which should render an AngII receptor antagonist inactive and abrogate the possibility of an ATR2-dependent protective shift in signaling activities. However, losartan triggered a dose- and time-dependent increase in NO release (Figure 4, A and B). A report has shown how losartan can directly activate the VEGFR2-eNOS pathway in an AngII/ ATR1-independent manner, ${ }^{35}$ which may activate eNOSdependent NO release and inhibit pathological TGF- $\beta$ signaling. ${ }^{36}$ VEGFR2 knockdown blocked such effect (Figure 4, C and D), confirming the dependence on a VEGFR2-dependent complex in losartan's NO-releasing activities, as suggested. ${ }^{35}$ ATR2 blocker PD 123319 had no effect, as expected (data not shown). This suggests that losartan can activate eNOS and NO release in an ATR1independent manner, as shown by others. ${ }^{35}$

The protective role of eNOS was confirmed by breeding MFS mice to a strain expressing a form of endogenous eNOS with the phosphorylated mimetic S1176D mutation. ${ }^{37}$ This caused a $46 \%$ decrease in aortic root enlargement compared with MFS mice (Figure 5A) and elastic fiber fragmentation similar to losartan treatment and corrected noncanonical TGF- $\beta$ signaling (extracellular signalregulated kinase phosphorylation), ${ }^{9}$ with near-complete inhibition of ascending aorta enlargement, another phenotype of the MFS mouse used (Figure 5B and Supplemental Figure S4). In contrast, substitution with phosphorylated inactive S1176A eNOS caused a nonsignificant increase in MFS aortic root diameter (Figure 5C). Finally, the hemizygous eNOS overexpression model ${ }^{17}$ (Figure 5D) significantly reduced (by 58\%) MFS aortic root widening, further supporting the capacity of eNOS to block aortic root remodeling. None of the eNOS transgenic lines caused a significant change in WT aortic root diameter. eNOS activity was confirmed by using a pharmacologic approach that targets endogenous eNOS. Indeed, endogenous eNOSspecific activation with CavNOxin, a caveolin-1 peptide antagonist (Figure 5E) capable of activating eNOS specifically, ${ }^{19}$ significantly decreased MFS-associated aortic root aneurysm by $60 \%$. Taken together, our results show that increased eNOS-dependent endothelial function can prevent aortic root disease in this MFS model (Figure 5F). In addition, this supports the hypothesis that losartan may have eNOS-driven off-target effects, as suggested by the absence of protective ATR2 shift in MFS/ATR $1 \mathrm{a}^{-1-}$ mice (Figures 1 and 2) and L-NAME-dependent inhibition of NO release, which renders losartan inactive.

\section{Discussion}

Overall, the findings presented herein illustrate the broad aspect of losartan-based pharmacotherapy in MFS and help 
A
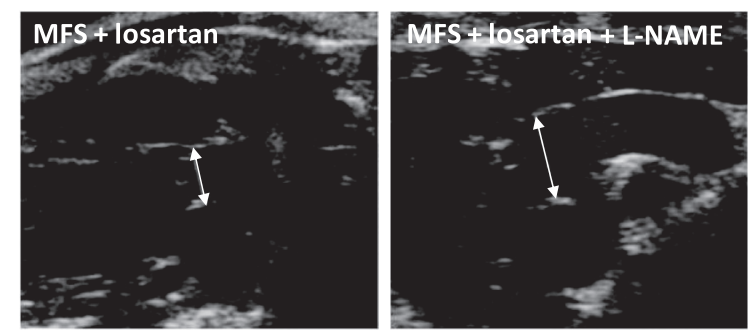

C

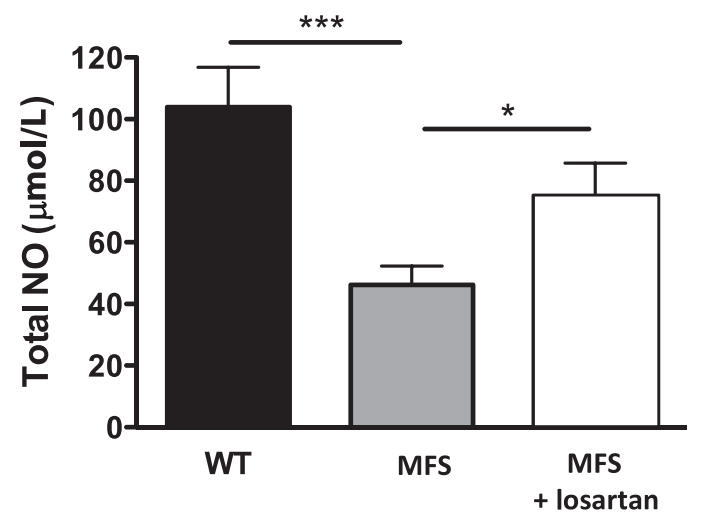

B
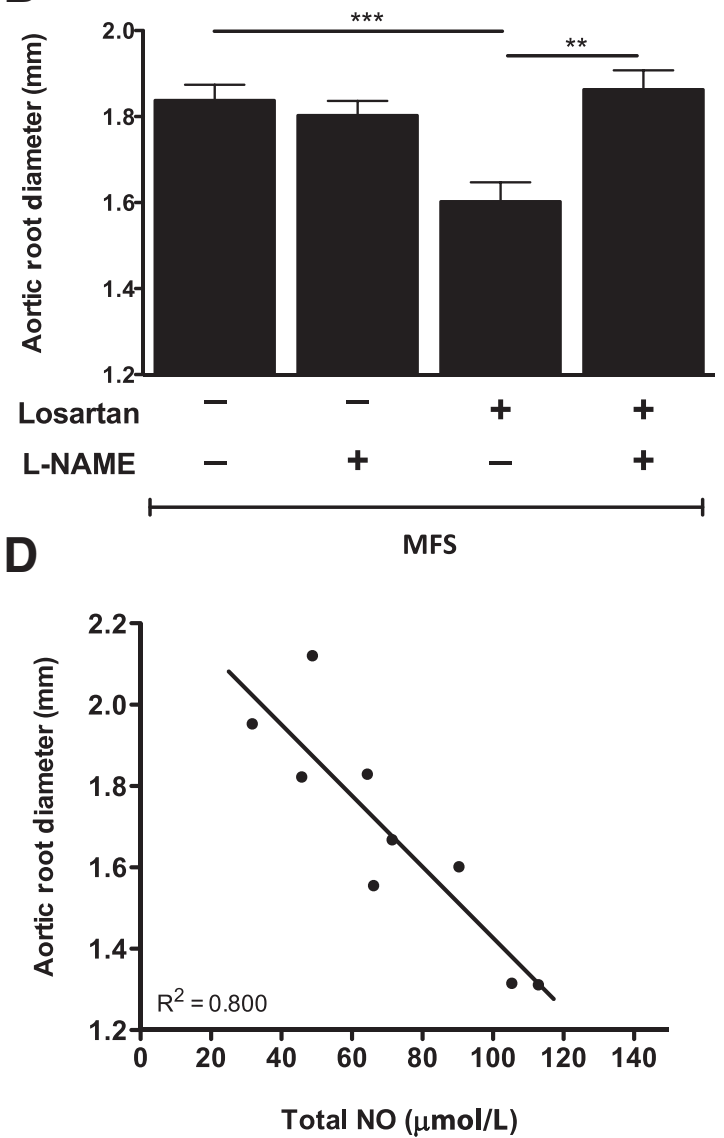

Figure 3 Losartan acts through a nitric oxide synthase (NOS)-dependent mechanism. A and B: Combination treatment with losartan and NOS inhibitor LNAME blocks the effect of losartan on aortic root widening (double-headed arrows) at 3 months of age, wherein aortic root diameters are determined from multiple measurements by a blinded technician. C: Total plasma NO levels in wild-type (WT), Marfan syndrome (MFS), and losartan-treated MFS mice were determined at 6 months of age in fasted mice and show significant reduction in NO in MFS mice that is corrected with losartan. D: A relationship is seen between aortic root diameter and total plasma N0 at 6 months of age. Data are expressed as means \pm SEM (B). $n=9$ MFS $(\mathbf{A}-\mathbf{C}) ; n=5$ MFS + L-NAME, MFS + losartan, and MFS + losartan + L-NAME $(\mathbf{A}-\mathbf{C})$ and WT (C). ${ }^{*} P<0.05,{ }^{*} P<0.01$, and ${ }^{* * *} P<0.001$ (analysis of variance and $t$-test).

rationalize the pathogenesis and controversy surrounding management of MFS given recent large clinical trial results. ${ }^{12}$ Our findings that chronically hypotensive MFS mice with a decreased HR, lacking AngII vasopressor responses and aortic root ATR1a expression, undergo normal MFS progression support the ill-defined concept that lowering of blood pressure and afterload to attenuate aortic wall stress is not of therapeutic significance in MFS. ${ }^{13}$ A protective shift toward ATR2 signaling or increased losartan sensitivity was not observed in these MFS mice with blunted ATR1a expression. These findings suggested that protective ATR2 signaling might be more complex to trigger than initially believed, particularly if aortic root expression of ATR2 is as low as these data suggest. Considering others have also observed the antiaortic root remodeling effect of losartan in MFS without changes in blood pressure, ${ }^{13}$ these data depict a smaller contribution of the AngII system and its receptors in the vascular manifestations of MFS. This further supports the widespread belief that angiotensin-converting enzyme inhibitors are not relevant for MFS aortic root disease management. ${ }^{7,13}$ In contrast, data on MFS cardiomyopathy obtained with the cardiac-centric MgR MFS model ${ }^{15}$ show a clear dependence on ATR1a signaling activities. This suggested that the heart and aortic root behave differently in MFS, which may be explained by their different function, type of muscle tissues, and even embryonic origins. ${ }^{38}$ The unique clinical challenge posed by aortic root pathology is further exemplified by a recent report showing protection against MFS-associated ascending and thoracic aorta dilation with L-NAME ${ }^{39}$ because of the presence of proinflammatory inducible NOS. These data support the complexity of aortic root disease management compared with other more predictable sections of the aorta and suggest that the enzymatic source of $\mathrm{NO}$ is as important as the tissue from which it originates.

Because MFS mice lacking ATR1a do not show protection against MFS aortic root disease or increased losartan sensitivity - key components of a protective ATR2-dependent switch in AngII signaling - and because L-NAME can block losartan's effect on aortic root widening, off-target 


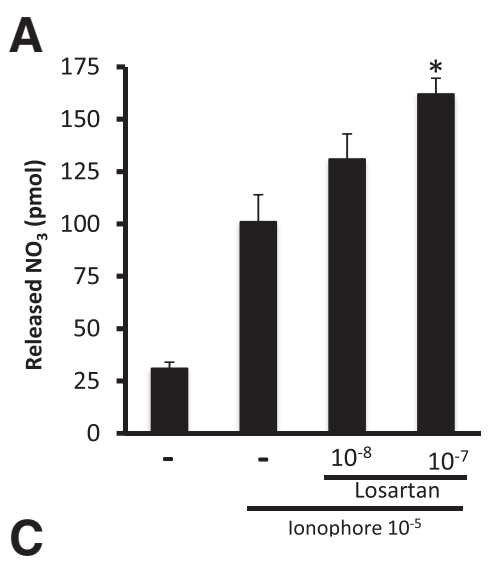

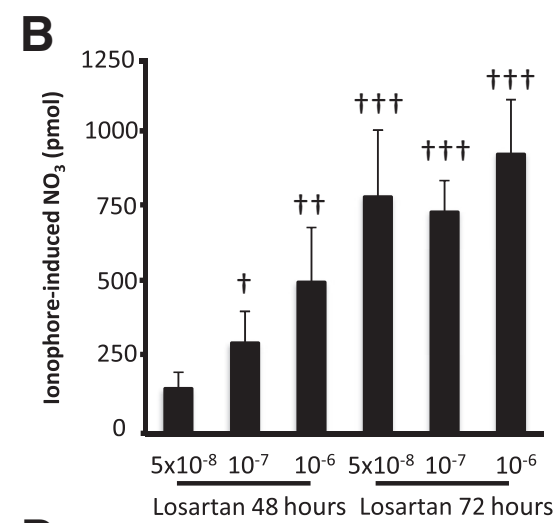

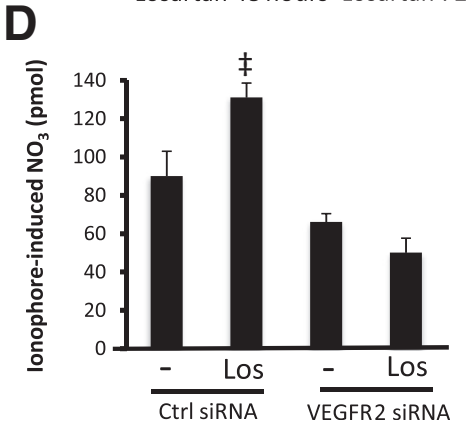

Figure 4 Losartan increases endothelial cell nitric oxide release in a vascular endothelial growth factor receptor-2 (VEGFR2)-dependent manner. A and B: Losartan increases dose dependently ionophore-induced nitrate release $\left(\mathrm{NO}_{3}^{-}\right)$in culture endothelial cells under acute (1 hour) and chronic (48 to 72 hours) conditions, with control values subtracted. C and D: Western blots showing decreased VEGFR2 expression (250$\mathrm{kDa}$ marker) in endothelial cells treated with VEGFR2 silencing RNA. Heat shock protein 90 is used as loading control (Ctrl). VEGFR2 siRNAtreated endothelial cells showed no increase in ionophore-induced nitrate with acute losartan (Los) treatment. For ionophore-induced nitrate studies, values represent 1-hour accumulation of nitrate for pretreated cells and 15-minute accumulation for acutely treated cells. Data show release, with each condition performed in triplicate. Data are expressed as means $\pm \operatorname{SEM}(\mathbf{A}, \mathbf{B}$, and $\mathbf{D}$ ). ${ }^{*} P<0.05$ versus ionophore (analysis of variance and $t$-test); ${ }^{\dagger} P<0.05,{ }^{\dagger \dagger} P<0.01$, and ${ }^{\dagger \dagger} P<0.001$ versus unstimulated cells (analysis of variance and $t$-test); ${ }^{\ddagger} P<0.05$ versus ctrl siRNA (analysis of variance and $t$-test).
NO-dependent actions of losartan were examined. This is a concept supported by reports from our group describing how losartan can correct vascular function in MFS mice and increase flow-mediated dilation in MFS patients. ${ }^{32,33}$ Losartan can trigger activation of the eNOS NO release independently of AngII, which is consistent with reports of ATR1 blockers triggering ATR1-independent signaling activities, ${ }^{40}$ and losartan can activate the VEGFR2 and Akt pathways in absence of AngII in cells lacking ATR $1 .^{35}$ The in vitro and in vivo mechanisms are poorly understood, because losartan's off-target signaling activities are complex. ${ }^{41}$ Besides known secondary effectors, ${ }^{42}$ VEGFR2 signals downstream through a range of adapter molecules that include c-Src and VRAP, among many others. ${ }^{43}$ Which one binds to losartan and whether losartan alone can activate eNOS or only potentiate the signaling activity of a primary NO activator, such as laminar flow, warrant further investigation, particularly in vivo. Use of anti-VEGF therapeutic bevacizumab comes with a Food and Drug Administration warning of aortic aneurysm and is linked to lung airspace enlargement, two phenotypes of MFS. ${ }^{44-46}$ Because of lack of eNOS-specific NO activating medications, our knowledge of the vascular effects of reversing endothelial dysfunction remains fragmental. Using the experimental eNOS-specific CavNOxin, we and others have shown that increased eNOS NO release can promote aortic smooth muscle cell quiescence, decreased inflammation, remodeling, and oxidative stress known to decrease TGF- $\beta$ signaling. ${ }^{19,31}$ TGF- $\beta$ is a controversial effector in MFS, ${ }^{47}$ despite antiaortic remodeling effects observed with anti-TGF- $\beta$ blocking antibodies ${ }^{8}$ and similarity of MFS to Loeys-Dietz syndrome. However, the potential off-target activity of losartan helps rationalize its anti-lung remodeling properties, ${ }^{14,48}$ although whether this therapeutic effect stems from activation of the NOS system remains to be confirmed. Lung epithelial cells express neuronal NOS and may express eNOS, whereas inducible NOS may be connective tissue disease dependent,${ }^{48,49}$ further stressing the complexity of the NOS system in tissue remodeling. Losartan has been linked to ATR1-independent activation of other cellular pathways ${ }^{41}$; whether these pathways play a role in losartan signaling in ECs or other cell types at the center of aortic wall remodeling, such as smooth muscle cells and adventitial fibroblasts, is unknown and was not investigated in the current study. The off-target effects of ATR1 blockers may also include anti-lung tissue remodeling properties because losartan was shown to attenuate cigarette smoke-induced emphysema, although loss of ATR1a in our current study did not prevent MFS-associated airspace widening. The nonvascular antiremodeling effects of losartan, which may also affect the skeletal manifestation of MFS, warrant further investigations.

From a patient outcome perspective, our data support the concept that blood pressure lowering in MFS is of little therapeutic value and propose to focus on gains in endothelial function. We and others have shown endothelial dysfunction in MFS aortas, which can be corrected with losartan in patients, ${ }^{33}$ and eNOS-specific up-regulation of endothelial function can trigger profound antiremodeling effects. ${ }^{29,50,51}$ Hence, prophylactic treatment of MFS aortic root disease may benefit from endothelial 
A

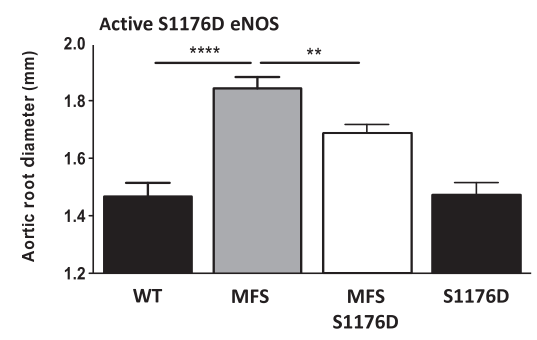

D

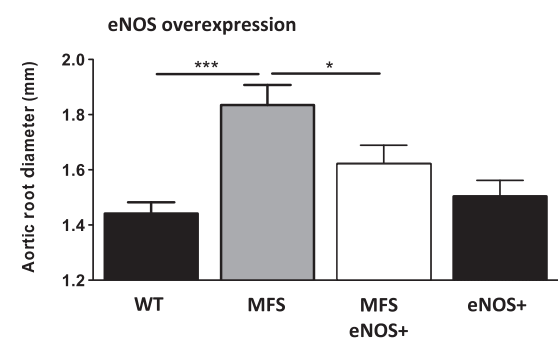

B

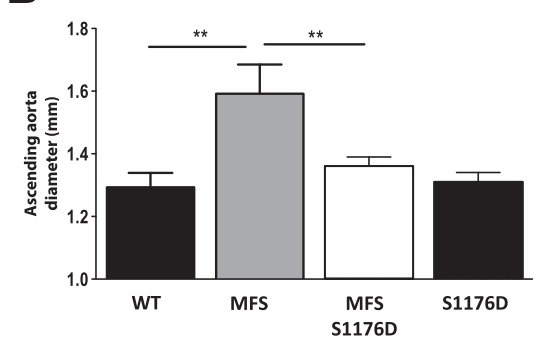

E

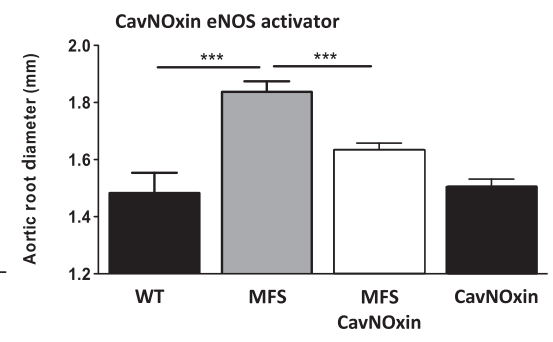

C

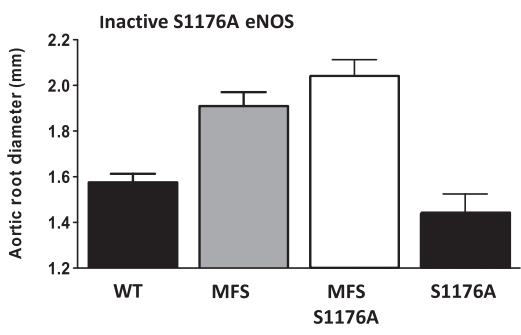

$\mathbf{F}$

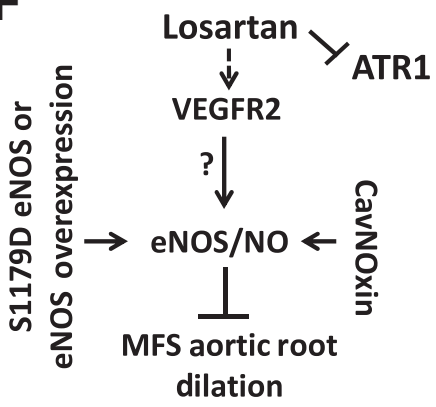

Figure 5 Increased endothelial nitric oxide synthase (eNOS) activity is therapeutically relevant in Marfan syndrome (MFS) models. A and B: MFS mice expressing a constitutively active eNOS mutant [eNOS 1176 Ser-to-Asp knock-in (S1176D)] show attenuated aortic root and ascending aorta widening. C: An inactive eNOS mutant [eNOS 1176 Ser-to-Ala knock-in (S1176A)] causes nonsignificant increase in aortic root diameter (MFS S1176A) relative to MFS controls. D and E: Overexpression of eNOS transgene (eNOS Tg) also reduces aortic root aneurysm (D), as does treatment with eNOS-activator caveolin-1 peptide mimetic (CavNOxin; E). Quantification of aortic root diameter via echocardiograms represents mean group aortic root diameter and quantification of total N0. A represents averages of $n>5$ biological replicates averaged from assays completed in technical duplicate. F: Losartan may act in a vascular endothelial growth factor receptor-2 (VEGFR2)-dependent manner to stimulate NO production through eNOS-a key antiaortic root remodeling enzyme, as confirmed using multiple models - and this effect is likely independent of its ATR1 blocking activities. Data are expressed as means \pm SEM (A-E). $n=11$ WT (A and B); $n=15$ MFS (A and B); $n=13$ MFS S1176D (A and B); $n=9$ S1176D (A and B), WT (C), and MFS (E); $n=10$ MFS (C and D), $n=5$ MFS S1176A and S1176A (C); $n=7$ WT, MFS eNOS Tg ${ }^{+}$, and eNOS Tg ${ }^{+}$(D); $n=6$ WT and WT + CavNOxin (E). ${ }^{*} P<0.05,{ }^{*} P<0.01, * * * P<0.001$, and ${ }^{* * * *} P<0.0001$ (analysis of variance and $t$-test). WT, wild-type.

function-optimized approaches, a claim also supported by the protective effect of mild aerobic exercise on MFS aortic root disease. ${ }^{52}$ Although exercise also reduces resting HR, the effect of ATR1a deletion on C1039G mice HR did not reduce aortic root remodeling, further supporting the role of endothelial NO in MFS. Hence, exercise and other welloptimized endothelial function-enhancing approaches may prove superior to commonly used therapies, a controversial topic in a recent large-scale trial. ${ }^{12}$ Our groups have shown that losartan and atenolol differ in their effect on endothelial function, ${ }^{33}$ which raises the possibility of titrating losartan against endothelial function, similarly to atenolol titration against HR, as suggested by current guidelines. Such difference in mechanism of action may rationalize the synergies observed with a high dose of losartan in combination with atenolol compared with atenolol alone in MFS patients. ${ }^{53}$ To err on the side of caution, the mouse experiments did not include blood NO levels in ATR1a-null mice after losartan treatment. In addition, the data were obtained in a standardized MFS model mimicking the most common type of human FBN1 with homogeneous response to losartan, whereas MFS patients may show greater heterogeneity on the basis of their underlying FBN1 mutation. To our knowledge, this study may be the first to identify an animal model of human disease in which a clinically available medication triggers an entirely endothelial function-based therapeutic effect. Our findings may have implications beyond our understanding of MFS, because they also support potential off-target effects of losartan on protective endothelial function in non-AngIIdriven diseases.

\section{Acknowledgments}

We thank Lubos Bohunek and Tatjana Bozin for assistance with animal studies, Dr. Tillie Hackett for mechanistic insights, and Dr. Harry Dietz for assistance in the early phase of this project and angiotensin II receptor type 1 expression studies.

S.L.S. designed and performed most experiments; S.L.S., R.C., and P.B. completed nitric oxide release studies; N.M., M.M., R.C., U.J., and J.A.H. assisted S.L.S. with animal studies; M.A.S. and S.L.S. evaluated and scored histology; P.L.H. and R.d.C. provided assistance with animal model development; G.G.S. was responsible for patient data; C.V.B., J.C.H., M.E., M.A.S., S.L.S., and P.B. completed experimental design; S.L.S. wrote the manuscript, with assistance from P.B., M.A.S., J.A.H., J.C.H., M.E., and C.V.B. 


\section{Supplemental Data}

Supplementary data related to this article can be found at https://doi.org/10.1016/j.ajpath.2017.11.006.

\section{References}

1. Robinson PN, Godfrey M: The molecular genetics of Marfan syndrome and related microfibrillopathies. J Med Genet 2000, 37:9-25

2. Jones JA, Spinale FG, Ikonomidis JS: Transforming growth factorbeta signaling in thoracic aortic aneurysm development: a paradox in pathogenesis. J Vasc Res 2009, 46:119-137

3. De Paepe A, Devereux RB, Dietz HC, Hennekam RC, Pyeritz RE: Revised diagnostic criteria for the Marfan syndrome. Am J Med Genet 1996, 62:417-426

4. Nollen GJ, Groenink M, van der Wall EE, Mulder BJ: Current insights in diagnosis and management of the cardiovascular complications of Marfan's syndrome. Cardiol Young 2002, 12:320-327

5. Halpern BL, Char F, Murdoch JL, Horton WB, McKusick VA: A prospectus on the prevention of aortic rupture in the Marfan syndrome with data on survivorship without treatment. Johns Hopkins Med J 1971, 129:123-129

6. Murdoch JL, Walker BA, Halpern BL, Kuzma JW, McKusick VA: Life expectancy and causes of death in the Marfan syndrome. N Engl J Med 1972, 286:804-808

7. Habashi JP, Judge DP, Holm TM, Cohn RD, Loeys BL, Cooper TK, Myers L, Klein EC, Liu G, Calvi C, Podowski M, Neptune ER, Halushka MK, Bedja D, Gabrielson K, Rifkin DB, Carta L, Ramirez F, Huso DL, Dietz HC: Losartan, an AT1 antagonist, prevents aortic aneurysm in a mouse model of Marfan syndrome. Science 2006, 312:117-121

8. Neptune ER, Frischmeyer PA, Arking DE, Myers L, Bunton TE, Gayraud B, Ramirez F, Sakai LY, Dietz HC: Dysregulation of TGFbeta activation contributes to pathogenesis in Marfan syndrome. Nat Genet 2003, 33:407-411

9. Singh MN, Lacro RV: Recent clinical drug trials evidence in Marfan syndrome and clinical implications. Can J Cardiol 2016, 32:66-77

10. Phomakay V, Huett WG, Gossett JM, Tang X, Bornemeier RA, Collins RT 2nd: $\beta$-Blockers and angiotensin converting enzyme inhibitors: comparison of effects on aortic growth in pediatric patients with Marfan syndrome. J Pediatr 2014, 165:951-955

11. Brooke BS, Habashi JP, Judge DP, Patel N, Loeys B, Dietz HC 3rd: Angiotensin II blockade and aortic-root dilation in Marfan's syndrome. N Engl J Med 2008, 358:2787-2795

12. Lacro RV, Dietz HC, Sleeper LA, Yetman AT, Bradley TJ, Colan SD, Pearson GD, Selamet Tierney ES, Levine JC, Atz AM, Benson DW, Braverman AC, Chen S, De Backer J, Gelb BD, Grossfeld PD, Klein GL, Lai WW, Liou A, Loeys BL, Markham LW, Olson AK, Paridon SM, Pemberton VL, Pierpont ME, Pyeritz RE, Radojewski E, Roman MJ, Sharkey AM, Stylianou MP, Wechsler SB, Young LT, Mahony L; Pediatric Heart Network Investigators: Atenolol versus losartan in children and young adults with Marfan's syndrome. N Engl J Med 2014, 371:2061-2071

13. Habashi JP, Doyle JJ, Holm TM, Aziz H, Schoenhoff F, Bedja D, Chen Y, Modiri AN, Judge DP, Dietz HC: Angiotensin II type 2 receptor signaling attenuates aortic aneurysm in mice through ERK antagonism. Science 2011, 332:361-365

14. Podowski M, Calvi C, Metzger S, Misono K, Poonyagariyagorn H, Lopez-Mercado A, Ku T, Lauer T, McGrath-Morrow S, Berger A, Cheadle C, Tuder R, Dietz HC, Mitzner W, Wise R, Neptune E: Angiotensin receptor blockade attenuates cigarette smoke-induced lung injury and rescues lung architecture in mice. J Clin Invest 2012, 122:229-240

15. Cook JR, Carta L, Benard L, Chemaly ER, Chiu E, Rao SK, Hampton TG, Yurchenco P; GenTAC Registry Consortium,
Costa KD, Hajjar RJ, Ramirez F: Abnormal muscle mechanosignaling triggers cardiomyopathy in mice with Marfan syndrome. J Clin Invest 2014, 124:1329-1339

16. Kashiwagi S, Atochin DN, Li Q, Schleicher M, Pong T, Sessa WC, Huang PL: eNOS phosphorylation on serine 1176 affects insulin sensitivity and adiposity. Biochem Biophys Res Commun 2013, 431: 284-290

17. van Haperen R, Cheng C, Mees BM, van Deel E, de Waard M, van Damme LC, van Gent T, van Aken T, Krams R, Duncker DJ, de Crom R: Functional expression of endothelial nitric oxide synthase fused to green fluorescent protein in transgenic mice. Am J Pathol 2003, 163:1677-1686

18. Bernatchez P, Sharma A, Bauer PM, Marin E, Sessa WC: A noninhibitory mutant of the caveolin-1 scaffolding domain enhances eNOS-derived NO synthesis and vasodilation in mice. J Clin Invest 2011, 121:3747-3755

19. Sharma A, Sellers S, Stefanovic N, Leung C, Tan SM, Huet O, Granville DJ, Cooper ME, de Haan JB, Bernatchez P: Direct eNOS activation provides atheroprotection in diabetes-accelerated atherosclerosis. Diabetes 2015, 64:3937-3950

20. Hirota JA, Ellis R, Inman MD: Regional differences in the pattern of airway remodeling following chronic allergen exposure in mice. Respir Res 2006, 7:120

21. Lee L, Cui JZ, Cua M, Esfandiarei M, Sheng X, Chui WA, Xu MH, Sarunic MV, Beg MF, van Breemen C, Sandor GG, Tibbits GF: Aortic and cardiac structure and function using high-resolution echocardiography and optical coherence tomography in a mouse model of Marfan syndrome. PLoS One 2016, 11:e164778

22. Bernatchez PN, Bauer PM, Yu J, Prendergast JS, He P, Sessa WC: Dissecting the molecular control of endothelial NO synthase by caveolin-1 using cell-permeable peptides. Proc Natl Acad Sci U S A 2005, 102:761-766

23. Gembardt F, Heringer-Walther S, van Esch JH, Sterner-Kock A, van Veghel R, Le TH, Garrelds IM, Coffman TM, Danser AH, Schultheiss HP, Walther T: Cardiovascular phenotype of mice lacking all three subtypes of angiotensin II receptors. FASEB J 2008, 22: 3068-3077

24. Ito M, Oliverio MI, Mannon PJ, Best CF, Maeda N, Smithies O, Coffman TM: Regulation of blood pressure by the type 1A angiotensin II receptor gene. Proc Natl Acad Sci U S A 1995, 92:3521-3525

25. Matt P, Schoenhoff F, Habashi J, Holm T, Van Erp C, Loch D, Carlson OD, Griswold BF, Fu Q, De Backer J, Loeys B, Huso DL, McDonnell NB, Van Eyk JE, Dietz HC; GenTAC Consortium: Circulating transforming growth factor-beta in Marfan syndrome. Circulation 2009, 120:526-532

26. Wagenaar LJ, Voors AA, Buikema H, van Gilst WH: Angiotensin receptors in the cardiovascular system. Can J Cardiol 2002, 18: $1331-1339$

27. Herrera M, Sparks MA, Alfonso-Pecchio AR, Harrison-Bernard LM, Coffman TM: Response to lack of specificity of commercial antibodies leads to misidentification of angiotensin type- 1 receptor protein. Hypertension 2013, 61:e32

28. Herrera M, Sparks MA, Alfonso-Pecchio AR, Harrison-Bernard LM, Coffman TM: Lack of specificity of commercial antibodies leads to misidentification of angiotensin type 1 receptor protein. Hypertension 2013, 61:253-258

29. Wilson DG, Bellamy MF, Ramsey MW, Goodfellow J, Brownlee M, Davies S, Wilson JF, Lewis MJ, Stuart AG: Endothelial function in Marfan syndrome: selective impairment of flow-mediated vasodilation. Circulation 1999, 99:909-915

30. Chung AW, Au Yeung K, Cortes SF, Sandor GG, Judge DP, Dietz HC, van Breemen C: Endothelial dysfunction and compromised eNOS/Akt signaling in the thoracic aorta during the progression of Marfan syndrome. Br J Pharmacol 2007, 150:1075-1083

31. Barouch LA, Harrison RW, Skaf MW, Rosas GO, Cappola TP, Kobeissi ZA, Hobai IA, Lemmon CA, Burnett AL, O'Rourke B, Rodriguez ER, Huang PL, Lima JA, Berkowitz DE, Hare JM: Nitric 
oxide regulates the heart by spatial confinement of nitric oxide synthase isoforms. Nature 2002, 416:337-339

32. Yang H, Kim J, Chum E, van Breemen C, Chung A: Effectiveness of combination of losartan potassium and doxycycline versus single-drug treatments in the secondary prevention of thoracic aortic aneurysm in Marfan syndrome. J Thorac Cardiovasc Surg 2010, 140:305-312

33. Sandor GG, Alghamdi MH, Raffin LA, Potts MT, Williams LD, Potts JE, Kiess M, van Breemen C: A randomized, double blind pilot study to assess the effects of losartan vs. atenolol on the biophysical properties of the aorta in patients with Marfan and Loeys-Dietz syndromes. Int J Cardiol 2015, 179:470-475

34. Chung AW, Yang HH, Radomski MW, van Breemen C: Long-term doxycycline is more effective than atenolol to prevent thoracic aortic aneurysm in marfan syndrome through the inhibition of matrix metalloproteinase-2 and -9. Circ Res 2008, 102:e73-e85

35. Watanabe T, Suzuki J, Yamawaki H, Sharma VK, Sheu SS, Berk BC: Losartan metabolite EXP3179 activates Akt and endothelial nitric oxide synthase via vascular endothelial growth factor receptor-2 in endothelial cells: angiotensin II type 1 receptor-independent effects of EXP3179. Circulation 2005, 112:1798-1805

36. Saura M, Zaragoza C, Herranz B, Griera M, Diez-Marques L, Rodriguez-Puyol D, Rodriguez-Puyol M: Nitric oxide regulates transforming growth factor-beta signaling in endothelial cells. Circ Res 2005, 97:1115-1123

37. Atochin DN, Wang A, Liu VW, Critchlow JD, Dantas AP, LooftWilson R, Murata T, Salomone S, Shin HK, Ayata C, Moskowitz MA, Michel T, Sessa WC, Huang PL: The phosphorylation state of eNOS modulates vascular reactivity and outcome of cerebral ischemia in vivo. J Clin Invest 2007, 117:1961-1967

38. Cheung C, Bernardo AS, Trotter MW, Pedersen RA, Sinha S: Generation of human vascular smooth muscle subtypes provides insight into embryological origin-dependent disease susceptibility. Nat Biotechnol 2012, 30:165-173

39. Oller J, Méndez-Barbero N, Ruiz EJ, Villahoz S, Renard M, Canelas LI, Briones AM, Alberca R, Lozano-Vidal N, Hurlé MA, Milewicz D, Evangelista A, Salaices M, Nistal JF, Jiménez-Borreguero LJ, De Backer J, Campanero MR, Redondo JM: Nitric oxide mediates aortic disease in mice deficient in the metalloprotease Adamts 1 and in a mouse model of Marfan syndrome. Nat Med 2017, 23:200-212

40. Siragusa M, Sessa WC: Telmisartan exerts pleiotropic effects in endothelial cells and promotes endothelial cell quiescence and survival. Arterioscler Thromb Vasc Biol 2013, 33:1852-1860

41. Rossi GP: Losartan metabolite EXP3179: an AT1-receptorindependent treatment strategy for patients with the metabolic syndrome. Hypertension 2009, 54:710-712
42. Gelinas DS, Bernatchez PN, Rollin S, Bazan NG, Sirois MG: Immediate and delayed VEGF-mediated NO synthesis in endothelial cells: role of PI3K, PKC and PLC pathways. Br J Pharmacol 2002, 137:1021-1030

43. Napione LAM, Bussolino F: VEGF-mediated signal transduction in tumor angiogenesis. Physiologic and Pathologic Angiogenesis: Signaling Mechanisms and Targeted Therapy. Edited by Simionescu D, Simionescu A. London: InTech, 2017

44. Abe K, Toba M, Alzoubi A, Ito M, Fagan KA, Cool CD, Voelkel NF, McMurtry IF, Oka M: Formation of plexiform lesions in experimental severe pulmonary arterial hypertension. Circulation 2010, 121: $2747-2754$

45. Baek SU, Kwon SI: Rupture of abdominal aortic aneurysm after intravitreal bevacizumab injection: a case report. J Med Case Rep 2014, 8:48

46. Kasahara Y, Tuder RM, Taraseviciene-Stewart L, Le Cras TD, Abman S, Hirth PK, Waltenberger J, Voelkel NF: Inhibition of VEGF receptors causes lung cell apoptosis and emphysema. J Clin Invest 2000, 106:1311-1319

47. Mallat Z, Ait-Oufella H, Tedgui A: The pathogenic transforming growth factor- $\beta$ overdrive hypothesis in aortic aneurysms and dissections: a mirage? Circ Res 2017, 120:1718-1720

48. Jackson CL, Lucas JS, Walker WT, Owen H, Premadeva I, Lackie PM: Neuronal NOS localises to human airway cilia. Nitric Oxide 2015, 44:3-7

49. Sherman TS, Chen Z, Yuhanna IS, Lau KS, Margraf LR, Shaul PW: Nitric oxide synthase isoform expression in the developing lung epithelium. Am J Physiol 1999, 276:L383-L390

50. Yang HHC, van Breemen C, Chung AWY: Vasomotor dysfunction in the thoracic aorta of Marfan syndrome is associated with accumulation of oxidative stress. Vasc Pharmacol 2010, 52:37-45

51. Syyong HT, Chung AWY, Yang HHC, van Breemen C: Dysfunction of endothelial and smooth muscle cells in small arteries of a mouse model of Marfan syndrome. Br J Pharmacol 2009, 156: $1597-1608$

52. Gibson CP, Nielsen C, Alex R, Cooper K, Farney M, Gaufin D, Cui JZ, van Breemen C, Broderick TL, Vallejo-Elias J, Esfandiarei M: Mild aerobic exercise blocks elastin fiber fragmentation and aortic dilatation in a mouse model of Marfan syndrome associated aortic aneurysm. J Appl Physiol (1985) 2017, 123: $147-160$

53. Chiu HH, Wu MH, Wang JK, Lu CW, Chiu SN, Chen CA, Lin MT, Hu FC: Losartan added to beta-blockade therapy for aortic root dilation in Marfan syndrome: a randomized, open-label pilot study. Mayo Clin Proc 2013, 88:271-276 